\title{
Proceeding
}

Supplementary Issue: Summer Conferences of Sports Science. First International Conference in Iraq on Sport for Peace, 4 April 2019. Baghdad Science Institute, Baghdad, Iraq.

\section{The mediating roles of green brand image and attitude of green branding in the relationship between attachment of green branding and excessive product packaging in Thai sports manufacturing firms}

\author{
CHAYANAN KERDPITAK $\square$, WITTHAYA MEKKHAM \\ Suan Sunandha Rajabhat University, Bangkok, Thailand
}

\begin{abstract}
The purpose of the study is to narrow down the identified research gap by testing the impact of excessive packaging on green brand attachment empirically. Moreover, the study has analysed the role of green brand image and green brand attitude as mediators in the specified relation. It is expected that the damages caused to brand images by the excessive packaging are revealed by the research findings. This can support the enterprises in the development of strategy for green product packaging from the perspective of consumers. To achieve the objectives of the current study the data is collected from the consumer of sports industry. The SEM-PLS is used to analyses the data. The findings of the study suggest that the focus of consumers is more on the issues for protecting environment regarding green brands. This financial burden of the consumers is increased through excessive packaging along with a lot of waste. the study addressed the damage, which can be caused to the brand. It has been revealed through results that there is negative relation of excessive packaging of product with the green brand attitude of consumer and green brand image awareness. The green brand attachment is influenced positively by the green brand image and green brand attitude. The green brand attachment of consumer is influenced by the green brand image and green brand attitude through excessive packaging of product. Keywords: Green; Brand; Sports; Thailand.
\end{abstract}

Cite this article as:

Kerdpitak, C., \& Mekkham, W. (2019). The mediating roles of green brand image and attitude of green branding in the relationship between attachment of green branding and excessive product packaging in Thai sports manufacturing firms. Journal of Human Sport and Exercise, 14(5proc), S2202-S2216. doi:https://doi.org/10.14198//hse.2019.14.Proc5.39

Corresponding author. Suan Sunandha Rajabhat University, Bangkok, Thailand.

E-mail: chayanan.ke@ssru.ac.th

Supplementary Issue: Summer Conferences of Sports Science. First International Conference in Iraq on Sport for Peace, 4 April 2019. Baghdad Science Institute, Baghdad, Iraq.

JOURNAL OF HUMAN SPORT \& EXERCISE ISSN 1988-5202

(c) Faculty of Education. University of Alicante

doi:10.14198/jhse.2019.14.Proc5.39 


\section{INTRODUCTION}

A number of solutions have been raised by several countries about the issue of global warming. Global warming is considered to have a significant influence climate change. It is crucial to have a control on the problem of greenhouse gas emissions (GHG).

This can be resolved through recycling of products. It has been claimed by the Environmental Protection Agency of United States that in 2014, total of 258 million tons of MSW (municipal solid waste) was generated in US (Challcharoenwattana \& Pharino, 2016). The largest amount of generated MSW was made up of the packaging and containers (29.7 percent). This is equal to 34.6 percent rate of recycling. An annual reduction of almost 181 million metric tons of $\mathrm{CO} 2$ emissions was done from the passenger cars more than 38 million. The GHG emissions are reduced because of recycling (Sorunmu, 2018). It has been stated by the 2008 report of National Environment Protection Council in Australia that the consumption increase was witnessed over last few years, which was consistent with the growth rate of GDP from 2003-2007. The problem of packaging recycling rate still exists. The packaging waste is dumped into landfills that causes land pollution and creates methane. It may go to the oceans and affect the marine life. Resultantly, the excessive packaging litter is crucial for those concerned with the issues of environment over recent years. Eco-friendly packaging can be promoted through establishing regulations and standards (Leonidou et al, 2016). Greening has been adopted by enterprises for different reasons including achievement of competitive advantage, law compliance, stakeholders' pressure, and top management initiatives (Dechprom \& Jermsittiparsert, 2018; Somjai \& Jermsittiparsert, 2019; Sutduean et al, 2019; Jermsittiparsert et al, 2019). The significance of establishing a green image has been perceived by enterprises to reflect that they are aware of their social and environmental responsibilities considering the intense competitions. Moreover, environmental issues are given considered by the green consumers and they make decisions for purchasing on green products. Several organizations have initiated to formulate green marketing strategy to achieve competitive advantage (Kushwaha \& Sharma, 2016). Moreover, the problems linked with the environment are increasing over the recent some years. Litter is created by excessive packaging, which cannot be dealt through recycling. The rate of recycling for packaging material is below 100 percent. There is need for organizations to consider the attraction and cost of packaging first while making the strategy about product packaging. When plastic bottles are discarded, consumers feel guilty. Consumers are concerned about the problems of excessive packaging the impact created on environment (Magnier \& Schoormans, 2015). The problem of branded litter is involved by the above stated issues experienced by the organizations. The benefit and ability of green packaging and green marketing is focused by the previous research (Banerjee, 2017; Dangelico \& Vocalelli, 2017). However, a limited number of studies have worked on analysing the issue of branded litter, which is caused by excessive packaging and its influence on the brand repute and consumer perception. For consumers, the excessive packaging and eco-friendliness are two complex issues related to environment. Uncertainty prevails in this regard. The purpose of the study is to narrow down the identified research gap by testing the impact of excessive packaging on green brand attachment (GBATCH) empirically. Moreover, the study has analysed the role of GRIM and green brand attitude (GBAT) as mediators in the specified relation (Ryu, 2017; Sasmita \& Mohd Suki, 2015). It is expected that the damages caused to brand images by the excessive packaging are revealed by the research findings. This can support the enterprises in the development of strategy for green product packaging from the perspective of consumers.

\section{LITERATURE REVIEW}

An important element of a brand and product is its packaging (Doszhanov \& Ahmad, 2015). The packaging of a product reflects is attributes. The product packaging is protective, attracted, and easier to unwrap. The 
green packaging of product is rather different from normal packaging. The word green is referred as something, which is safe for the environment (Doszhanov \& Ahmad, 2015). Therefore, a green packaging can be regarded as the one using recycled resources and it creates less damage to the environment during its life cycle. Therefore, the environment is not damaged by the green products. These can be recycled because of the reusable, recycling, and degradable materials. Excessive packaging has not been defined by any official source. It can be regarded as the packaging, which gives on additional weight to the product or it can be costly/large/flattering etc.

\section{GBAT}

The most effective $A B C$ attitude model was proposed. According to him, the reflection of likes and dislikes of consumers is the affective component (Keller, 2016). The experiences about the object attitude are referred by the behavioural component. The thoughts, beliefs, and attributes related to an object are reflected by the cognitive component. A number of studies have adopted ABC model for development the eco attitudes to forecast the behaviours towards ecology (Choubak et al, 2019). The self-concept of an individual, focus on the environment, and self-consciousness for being the part of environment drives the eco attitude. The brand attitude is referred as the automatic effective reaction towards an object that is the subjective feeling of an individual for the entire brand (Charlton \& Cornwell, 2019). The concepts of environmental sustainability and brand attitude are integrated in this research for defining the eco-attitude of consumer being the GBAT. This results in the entire judgment of green brand by the individual.

\section{GRIM}

The important factor of brand value is referred as brand image (Sasmita \& Mohd Suki, 2015). The concepts and brand associations are formed by brand image. A better message of the brand is created by a strong image of brand as compared with its competitors. When a product has high brand image, it is certain that it possesses greater value and quality. Therefore, the spiritual image is positively shaped. The consumers are facilitated to support the brand by revealing their self-identities by the symbolic meaning. The brand attitude of an individual is influenced along with the loyalty and frequency of purchasing (Love et al , 2016). The perception of consumer about a brand to be eco-friendly and sustainable is referred as brand image for the green brand (Sasmita \& Mohd Suki, 2015). Higher quality is perceived by consumers along with GRIM of a company when t provided products, which are eco-friendly.

\section{GBATCH}

The level of perception relation between the specific object and the individual is referred as attachment. It is the outcome of long-term association between the individual and brand. When the relation is close, the brand attachment becomes stronger. When an individual considers brand as his part, the attachment becomes brand-self connection (Loureiro et al, 2017). Further, when the affection and cognition of the relation of an individual and brand is reflected by a brand, it becomes brand prominence. Three types of consumptions of GBATCH are indicated by this research (Hwang et al, 2019). The firs type involves the purchase of green products for self-satisfaction and reflecting concern and positive contribution to the natural environment. The second consumption involves the purchase for enriching the self and linking the green image with the ideal self in future. The third consumption involves the purchasing for supporting oneself to solve issues.

\section{Prior Relevant Research Models}

The relation between brand evaluation and branded litter was analysed by. It was suggested that a negative brand message could be conveyed by the branded litter that creates an influence on the brand attitude of consumer, brand personality, and intention to purchase. One of the branded litters is excessive packaging of product. The relation between the GRIM, GBAT, and excessive packaging of product has been explored by 
(Sasmita \& Mohd Suki ,2015). The three staged effects model was built by (Pansari \& Kumar ,2017) about the research on brand management and behaviour of consumers. In the first stage, the knowledge and awareness about the consumer is established in cognitive stage. The belief and affection for consumer is constructed in the affective stage. In the third stage, the purchase is resulted by the behaviour stage. Brand image has been linked with brand awareness by most of the research studies. The brand attitude and eco attitude of consumer resulted in GBAT. Therefore, GRIM and GBAT has been used to evaluate the green brand awareness of consumers in the cognitive stage. GBATCH has been position in the affective stage. Keller proposed the brand equity model based on customers (Ansary \& Hashim, 2018). The perceptions of consumers about the brand are measured in four levels. These levels include identity of brand, meaning of brand, response of brand, image of green brand at the level of brand meaning level, attitude of green brand at the level of brand response, and attachment of green brand at the level of brand relationship.

\section{Hypothesis}

Consumer becomes conscious about the environment, when it is greatly involved in the issues of environment. This results in development of a positive attitude for the brands, which are environmentally sound. The problem of packaging waste has been realized by consumers. The situation of environment can be worsened by excessive packaging. It has been shown by a number of empirical studies that the attitude of consumer for environmental protection results from moral reasons. The immoral organizations will be boycott by the consumers and the purchasing decisions are changed. It was found by Thøgersen's research (Stø \& Strandbakken ,2017) that almost $75 \%$ of respondents to go for the products, which are environmentally safe. It is suggested by the behaviour theory that behaviour is directly determined by the subjective norms. The obligation belief for not using product having excessive packaging can be measured by the subjective norm of avoiding products, which can result in waste. The attitude of consumers is changed, when they realize that environment can be damaged by the excessive packaging. Therefore, subjective norms, beliefs, and cognition ability is developed to choose the products, which are packaged through eco-friendly strategy (Doran \& Larsen, 2016). Therefore, it has been asserted by this research that excessive product packaging (EXPP) is considered by consumers as unfriendly for the environment resulting in negative attitude of green brand. In this regard, the following hypothesis has been proposed.

Hypothesis 1: The EXPP is in significant relationship with the GBAT.

An important element of the product and brand is the packaging of product. The characteristics of a product are revealed by its packaging as it shows several factors linked with brand (Simmonds et al, 2018). These attributes create a brand image, which is unique. Therefore, it becomes a method for the marketing of brand. In order to develop relationship of brand and consumer, product packaging lasts for longer as compared with some other changing tactics of marketing. This can create a vivid image of brand (Suomi et al, 2018). The focus of consumers is more on the issues for protecting environment regarding green brands. This financial burden of the consumers is increased through excessive packaging along with a lot of waste. The GRIM is linked with negative impression resulting from brand litter. Moreover, it was discovered by (Jayaram \& Avittathur ,2015) and (Sasmita \& Mohd Suki ,2015) that when green initiatives are adopted by enterprises, the eco-friendliness and cost-effectiveness is increased. In the similar way, the band image is improved, and brand differentiation is created. It has been argued by this study that the image of green brand is affective by the EXPP in a negative way. In this way, the following research hypothesis has been developed:

Hypothesis 2: The EXPP is in significant relationship with the GRIM.

The concepts of brand attachment and brand attitude are not same rather confusing. The positive or negative evaluation of an individual for the brand is reflected by brand attitude and this can be developed in a short period (Ryu, 2017). However, the affective relation of an individual with the brand is referred as brand 
attachment. It refers to the willingness of the consumer to respond to the brand and it develops in long term. The development of brand attitude is done in the cognitive stage and brand attachment is developed in affective state based on the required time for development. The brand attitude has a weak association with the brand but the brand attachment improves the relationship and results in greater level of brand attitude (Ahn \& Back, 2018; Ryu, 2017). A brand is considered as a relationship partner, when it is linked with the consumer. This supports in the achievement of personal goals and the hardship experienced can be resolved by this. GBATCH has been defined by this study as the level of perceptive relation between a certain green brand and the consumers. When consumer makes a brand a part of his life, the affection and emotional features get involved along with trust, intimacy, commitment, and self-linkage creating a significant meaning for the development of consumer-brand association (Chen et al, 2017). Therefore, it has been proposed in this research that GBATCH is positively influenced by GBAT leading to the following research hypothesis. Hypothesis 3: The GBAT is in significant relationship with the GBATCH.

The consumer judges' value through brand. The products, which comply with their self-concept, are chosen by the consumers while those are rejected that are not up to their expectations and values. Brand avoidance has been categorized into three different types by (Suomi et al, 2018). The first category has been derived from the consumer's first experience, which was not satisfactory. The second is resulted from the identification avoidance when there was a mismatch between the brand image and one's identity. The third is derived from the moral avoidance when there is a conflict between the brand value and one's identity. The negative thoughts of consumer are resulted from brand avoidance and this reduces the level of brand attachment. The brand cognition of consumer is influenced by brand image, which refers to the brand association of consumer (Huang \& Sarigöllü, 2014). The consumer must be facilitated to considered brand as eco-friendly for establishing GRIM in a successful manner. When consumers consider the match of selfvalue and GRIM, it creates a stronger level of brand attachment (Sasmita \& Mohd Suki, 2015). Moreover, it was noted by Chen et al. (2017) that there is positive association between brand image and emotional brand attachment. The result was concluded from the analysis conducted through an online website of social network. Therefore, it is asserted by this research that GBATCH is positively affected by GRIM. Therefore, the following research hypothesis has been formulated.

Hypothesis 4: The GRIM is in significant relationship with the GBATCH.

The product is regarded by the consumer as a symbol of the goals, characteristics, ideals, and social types. Therefore, consumer purchase product for its symbolic representation and functions. In the symbolic meaning of product packaging, the environmental awareness, reputation, expertise, convenience, value, etc. are included (Chen et al., 2017). These factors enrich the value of brand and strengthen the inheritance $f$ brand. Moreover, it influences the relation of consumer and brand (Doszhanov \& Ahmad, 2015). The packaging of product can become an important element of the life of consumers and support them in judging the quality. This improves their relation and involvement with the brand. This is a crucial source of brand equity. It may not be easier to use product because of inconvenient packaging and results in negative impact on the relation of brand and consumer (Chen et al., 2017; Magnier \& Crié, 2015). From the perspective of environmental management, green products are supported by green consumers because of lower impact on the environment. Therefore, the anxiety is reduced for uncertain and unknown variables of the environment. In this way, consumer experiences a close attachment with the green brands. In case, consumers come to know about the excessive packaging of green brands resulting in higher litter, their decision is changed and leads to low emotional attachment to that brand. It has been argued in this study that there is positive relation between excessive packaging of product with $\mathrm{GBATCH}$. The following research hypothesis has been proposed based on above discussion:

Hypothesis 5: EXPP is significantly related to GRIM. 
It has been asserted by this study that GBATCH is negatively affected through excessive packaging of product. The negative relation of GBATCH and excessive packaging of product is mediated through GRIM and GBAT (Ryu, 2017; Sasmita \& Mohd Suki, 2015). The excessive packaging of product is antecedent in this framework of research and the GBATCH is the consequent. However, GRIM and GBAT are considered as the two partial mediators in this research. The misleading behaviour of a firm in green marketing field, which mislead consumers regarding the green products' environmental features is referred as Greenwash (Chen et al., 2017; Dangelico \& Vocalelli, 2017). Considering the significance of greenwash in the market, it has been argued by this research that GBAT is not significantly influenced through GRIM (Sasmita \& Mohd Suki, 2015). However, there is a positive association between brand attitude and brand image in the marketing field. Because of this, the path between GBAT and GRIM is taken out by this research.

Hypothesis 6: GRIM mediates the relationship between EXPP and GBATCH.

Hypothesis 7: GBAT mediates the relationship between EXPP and GBATCH.

\section{METHODOLOGY}

The consumer level has been used as the unit of analysis in this study. The questionnaire survey approach has been used in this study, which has been based on the findings of relevant literature studies. The results of the questionnaire will be used to test the research framework and formulated hypothesis. The content validity of the questionnaire is of high level in this study. For the purpose of data analysis, present study employed descriptive and inferential statistics. Descriptive statistics were obtained by using SPSS v.22.0. These statistics provide comprehensive understanding about demographic variables and profiles of the respondents. The central tendency and data variability were shown and discussed for further detail of the subject matter. Afterwards, the inferential analysis was carried out by employing Partial Least Square Structural Equation Modelling through Smart PLS 3.0. Subsequently, from nine selected public universities, the researcher collected a number of 700 questionnaires. During data screening process, 9 questionnaires having missing data were omitted. Thus, the remaining 351 useable questionnaires with $50.5 \%$ response rate were then further used to perform statistical procedures. This is in line with recommendation, who suggested above $30 \%$ as the satisfactory response rate. Regardless of the popularity of PLS-SEM in social and behavioural sciences as a statistical method to perform multivariate data analysis, its application in education sector has increased only recently. SEM groups refers to the methods of data analysis to investigate any existing relationship among observed and latent variables. Particularly, PLS-SEM application provide useful understanding of the certain phenomena which cannot be observed directly, such as abilities, perception, attitudes, characteristics, and intentions, that are often associated with education research. The structural equation modelling (SEM) generally integrates the factor analysis and linear regression. Two approaches are used to perform statistical analysis through SEM framework, these are covariance-based SEM (CB-SEM) and partial least square structural equation modelling (PLS-SEM). CB-SEM is a popular approach which is often applied to carry out statistical analysis using AMOS, MPLUS, and LISREL software. Each SEM type has different objectives, make different assumptions, and use different methods of estimation. PLS-SEM was advanced by (Sarstedt \& Cheah ,2019), to explain the variance in dependent variables through OLS estimation.

\section{RESULTS}

This study specifically employed PLS technique for the following reasons. 1) It is an effective approach for complex models involving several manifested and latent variables. 2) In terms of error term and residual distribution, PLS analysis has no stringent criteria. 3) This technique can also be applied to reflective and formative measurement models, as suggested by (Henseler et al ,2015). 4) PLS provide accurate explanation 
of measurement errors and effectively estimates the moderation or mediation effects (Carrión et al, 2016). PLS path models involving hierarchical constructs with disaggregation method or complex models with mediating and moderating effects can be ideally estimated through PLS path modelling (Hair et al, 2017). 5) PLS-SEM provides valid and comprehensive outcomes, as compared to other techniques which provide lucid findings but requires various other analysis to be performed separately (Mueller \& Hancock, 2018). Thus, the study preferred PLS path modelling over CB-SEM for the data analysis. The first step in PLS analysis is the estimation of measurement or outer model to assess indicator loadings of particular constructs. Therefore, to check the consistency of instruments used for measuring model constructs, a reliability test was conducted. In addition, validity test considers the respective instrument's ability of measuring a construct (Janadari et al, 2016). Besides, the measurement model also demonstrates the nature of relationship among observed and latent variables. Thus, the construct validity is established by estimating the instruments' convergent, content and discriminant validity (Hair et al , 2016).

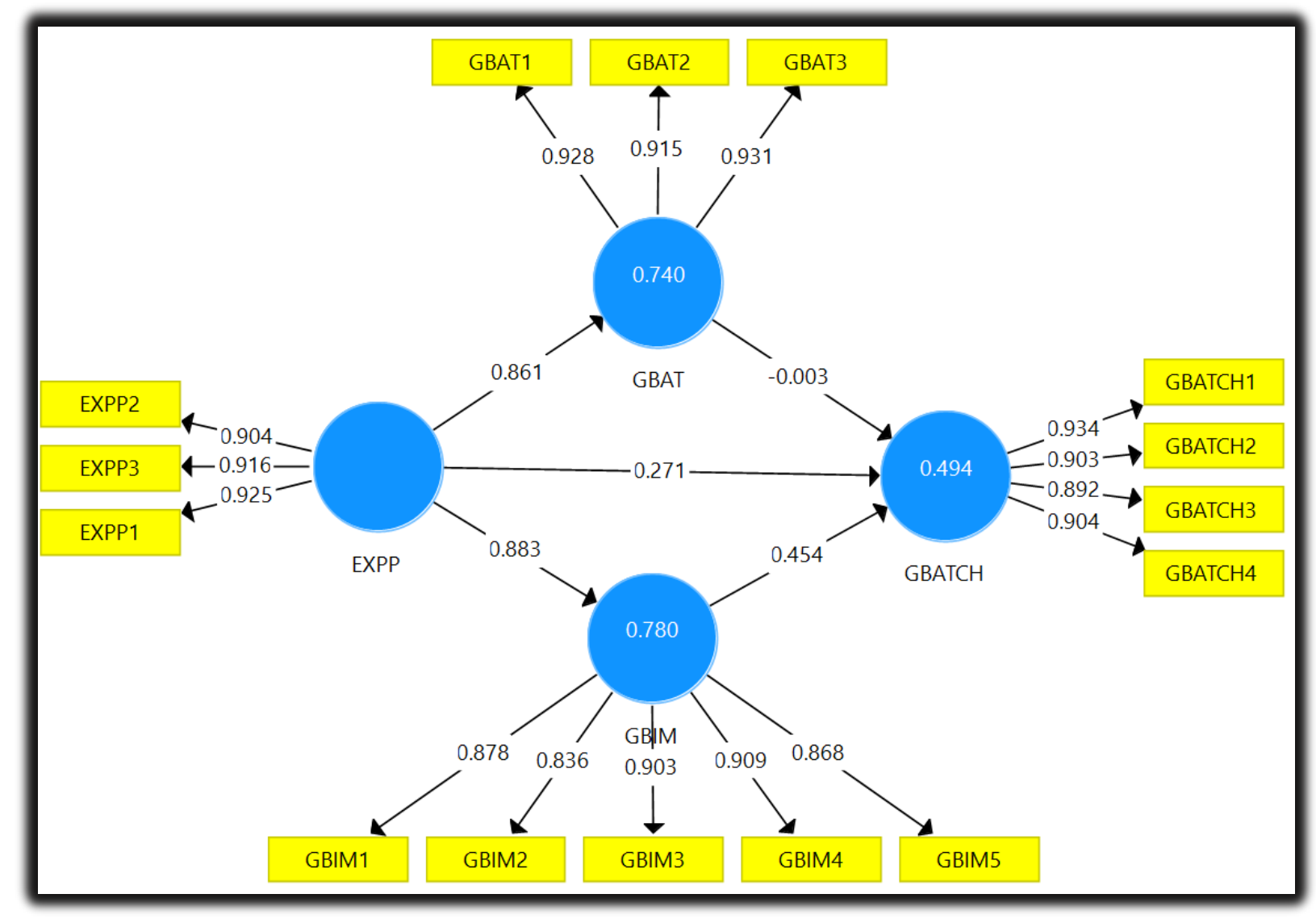

Figure 1. Measurement Model.

Afterwards, the outer loadings for all the individual constructs were computed to assess the items reliability using PLS-SEM technique. Commonly, items with 0.40-0.70 loadings are preserved (Hair et al , 2014), however, keeping those items which exhibit above or equal to 0.70 item loadings is more appropriate (Henseler et al., 2015). In view of (Henseler et al, 2015), less than 0.30 item loadings indicate poor loadings, within $0.31-0.50$ indicates fair loadings, within $0.51-0.60$ indicates moderate loadings, and within $0.61-0.80$ and $0.81-1.00$ indicate moderately strong and very strong loadings, respectively. However, item loadings must be above 0.30 or above score for mutual relationship. 
Table 1. Outer Loading.

\begin{tabular}{|l|l|l|l|l|}
\hline & EXPP & GBAT & GBATCH & GBIM \\
\hline EXPP2 & 0.904 & & & \\
\hline EXPP3 & 0.916 & & & \\
\hline GBAT1 & & 0.928 & & \\
\hline GBAT2 & & 0.915 & & \\
\hline GBAT3 & & 0.931 & & \\
\hline GBATCH1 & & & 0.934 & \\
\hline GBATCH2 & & & 0.903 & \\
\hline GBATCH3 & & & 0.892 & \\
\hline GBATCH4 & & & 0.904 & 0.878 \\
\hline GBIM1 & & & & 0.836 \\
\hline GBIM2 & & & & 0.903 \\
\hline GBIM3 & & & & 0.868 \\
\hline GBIM4 & & & & \\
\hline GBIM5 & & & & \\
\hline EXPP1 & 0.925 & & & \\
\hline
\end{tabular}

Convergent validity is defined as the extent that two measures that are theoretically related are actually found to be related even after the statistical analysis. However, the measures that are used for establishing convergent validity are average variance extracted (AVE), factor loadings, and composite reliability (Hair et al., 2014). Initially, the study analysed item loadings and obtained greater than 0.50 factor loadings for all items, which is consistent with the recommended level suggested by (Tzempelikos \& Gounaris ,2017) that is, the minimum acceptable range for item loadings is greater or equal to 0.50 . The item loading for only one item does not fall under the acceptable criteria, as shown in Table 2 Afterwards, the composite reliability was checked, it shows the extent to which an item reliably specifies the underlying construct. For all constructs in this study, $C R$ values were found between 0.872 and 0.968 , which were also consistent with the acceptable level of 0.70 as suggested by (Tzempelikos \& Gounaris, 2017). Subsequent to this, the degree of common variance between indicators was calculated which is termed as the average variance extracted (AVE) with a recommended level of 0.50 or above (Hair et al., 2017). The AVE values obtained for this research lies between $0.512-0.834$, which shows that the convergent validity is established. Table 2 shows the CR values for work commitment (to obtain the second-order construct). Since work commitment is the dependent variable in the reflective model, therefore, for this case composite reliability is suggested.

Table 2. Reliability.

\begin{tabular}{|l|l|l|l|l|}
\hline & Cronbach's Alpha & rho_A & CR & (AVE) \\
\hline EXPP & 0.902 & 0.903 & 0.939 & 0.837 \\
\hline GBAT & 0.915 & 0.917 & 0.946 & 0.855 \\
\hline GBATCH & 0.929 & 0.930 & 0.950 & 0.825 \\
\hline GBIM & 0.926 & 0.928 & 0.944 & 0.773 \\
\hline
\end{tabular}

The discriminant validity observes whether a particular measure is unrelated with other measures after performing the analysis. Discriminant validity confirms the construct validity of the measurement model, by observing the square roots of AVE's to the correlations between the latent constructs. The recommended score for AVE is greater or equal to 0.50 . Furthermore, AVE's square roots must exhibit greater values than the correlations between latent constructs. 
Table 3. Validity.

\begin{tabular}{|l|l|l|l|l|}
\hline & EXPP & GBAT & GBATCH & GBIM \\
\hline EXPP & 0.915 & & & \\
\hline GBAT & 0.861 & 0.899 & & \\
\hline GBATCH & 0.670 & 0.636 & 0.908 & \\
\hline GBIM & 0.883 & 0.893 & 0.691 & 0.879 \\
\hline
\end{tabular}

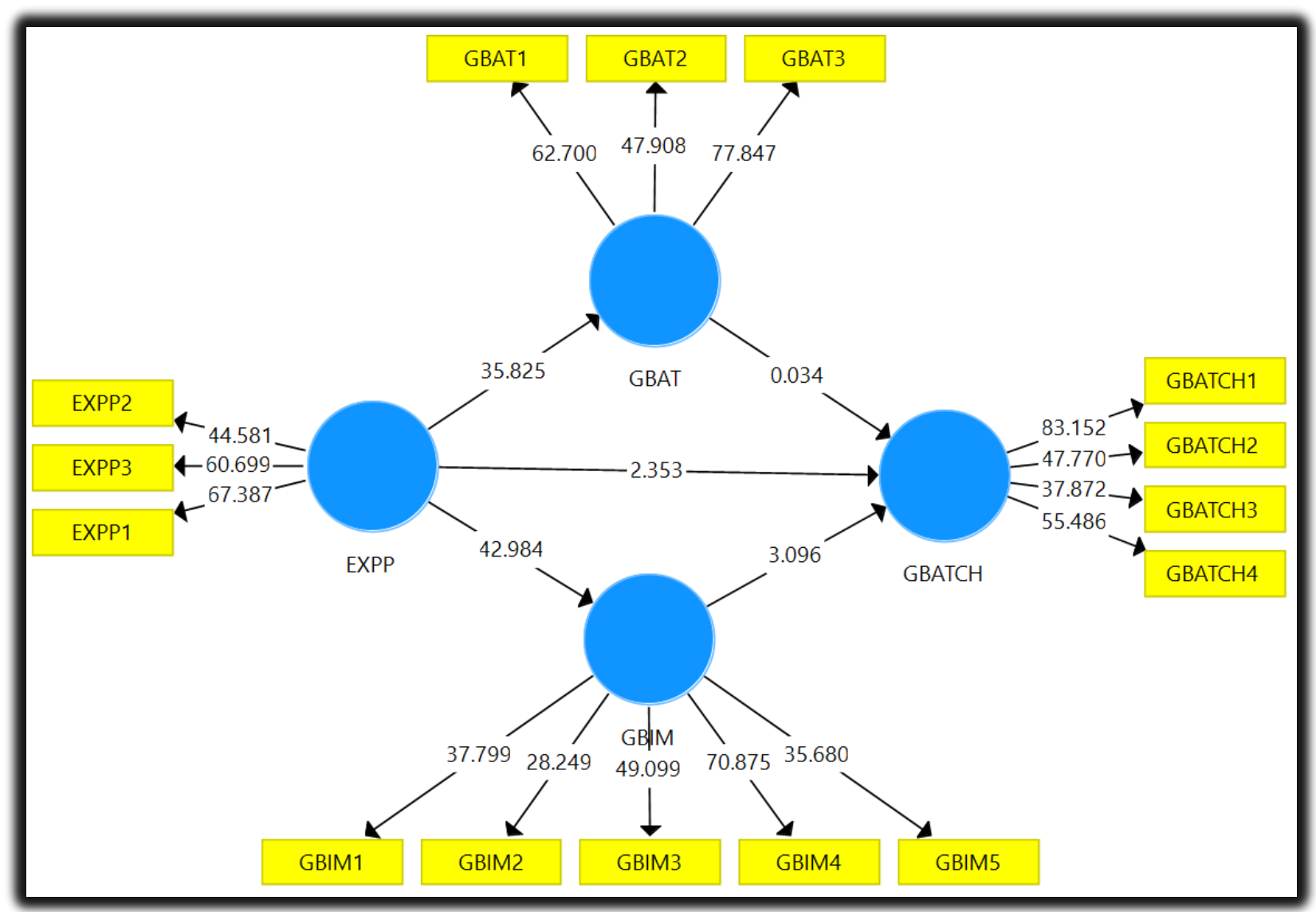

Figure 2. Structural Model.

Subsequent to outer model estimation, inner model was estimated which involves statistical testing of the proposed hypotheses, through estimating t-values and path-coefficients. A bootstrapping procedure was also applied in this study, using 500 resamples to determine the path coefficients' significance for testing the hypothesized relationships between the variables. (Ringle et al, 2018) suggested that bootstrap samples of 200-1000 are sufficient to incur adequate standard error estimates. 
Table 4. Direct Relationship.

\begin{tabular}{|l|l|l|l|l|l|}
\hline & $(\mathbf{0})$ & $(\mathbf{M})$ & $(\mathbf{S T D E V})$ & $(\mathbf{O} / \mathbf{S T D E V})$ & $\mathbf{P}$ Values \\
\hline EXPP $>>$ GBAT & 0.861 & 0.861 & 0.024 & 35.825 & 0.000 \\
\hline EXPP -> GBATCH & 0.271 & 0.271 & 0.115 & 2.353 & 0.009 \\
\hline EXPP - GBIM & 0.883 & 0.883 & 0.021 & 42.984 & 0.000 \\
\hline GBAT -> GBATCH & -0.003 & 0.007 & 0.097 & 0.034 & 0.486 \\
\hline GBIM $>$ GBATCH & 0.454 & 0.446 & 0.147 & 3.096 & 0.001 \\
\hline
\end{tabular}

Tale 5. Mediation.

\begin{tabular}{|l|l|l|l|l|l|}
\hline & $(\mathbf{O})$ & $(\mathbf{M})$ & $($ STDEV $)$ & $($ (|O/STDEV $\mid)$ & P Values \\
\hline EXPP -> GBAT -> GBATCH & -0.003 & 0.007 & 0.085 & 0.034 & $\mathbf{0 . 4 8 7}$ \\
\hline EXPP -> GBIM -> GBATCH & 0.401 & 0.393 & 0.128 & 3.127 & $\mathbf{0 . 0 0 1}$ \\
\hline
\end{tabular}

Observing the coefficient of determination or $\mathrm{R}^{2}$ value is an appropriate measure to assess structural model (Hair et al., 2014). $R^{2}$ value for the endogenous construct explains the model strength and describes proportion of variance in endogenous variable which is explained by the exogenous variables involved in the model. According to Ringle et al. (2018), the following R2 values i.e. 0.67, 0.33 and 0.19 are specified as large, medium and small, respectively. The $\mathrm{R}^{2}$ value for work commitment satisfies the recommended criteria, as shown in Table 6.

Table 6. R-square.

\begin{tabular}{|l|l|}
\hline & R Square \\
\hline GBAT & 0.740 \\
\hline GBATCH & 0.494 \\
\hline GBIM & 0.780 \\
\hline
\end{tabular}

Lastly, model's predictive relevance was determined to measure the quality of the model (Hair et al., 2016). For model's predictive quality, cross-validated redundancy measure $\left(Q^{2}\right)$ can be employed. This measure is a sample re-using technique, which explains that $Q^{2}>0$ specifies model's predictive relevance for endogenous construct.

In addition, blindfolding method is also used in PLS software to determine the predictive relevance. For estimating parameters, few cases were carefully handled and omitted from the analysis as missing values (Hair et al., 2014; Ringle et al., 2018).

Table 7. Blindfolding.

\begin{tabular}{|l|l|l|l|}
\hline & SSO & SSE & $\mathbf{Q}^{2}(=1-$ SSE/SSO) \\
\hline EXPP & 651.000 & 651.000 & \\
\hline GBAT & 651.000 & 257.352 & 0.605 \\
\hline GBATCH & 868.000 & 537.036 & 0.381 \\
\hline GBIM & $1,085.000$ & 466.326 & 0.570 \\
\hline
\end{tabular}




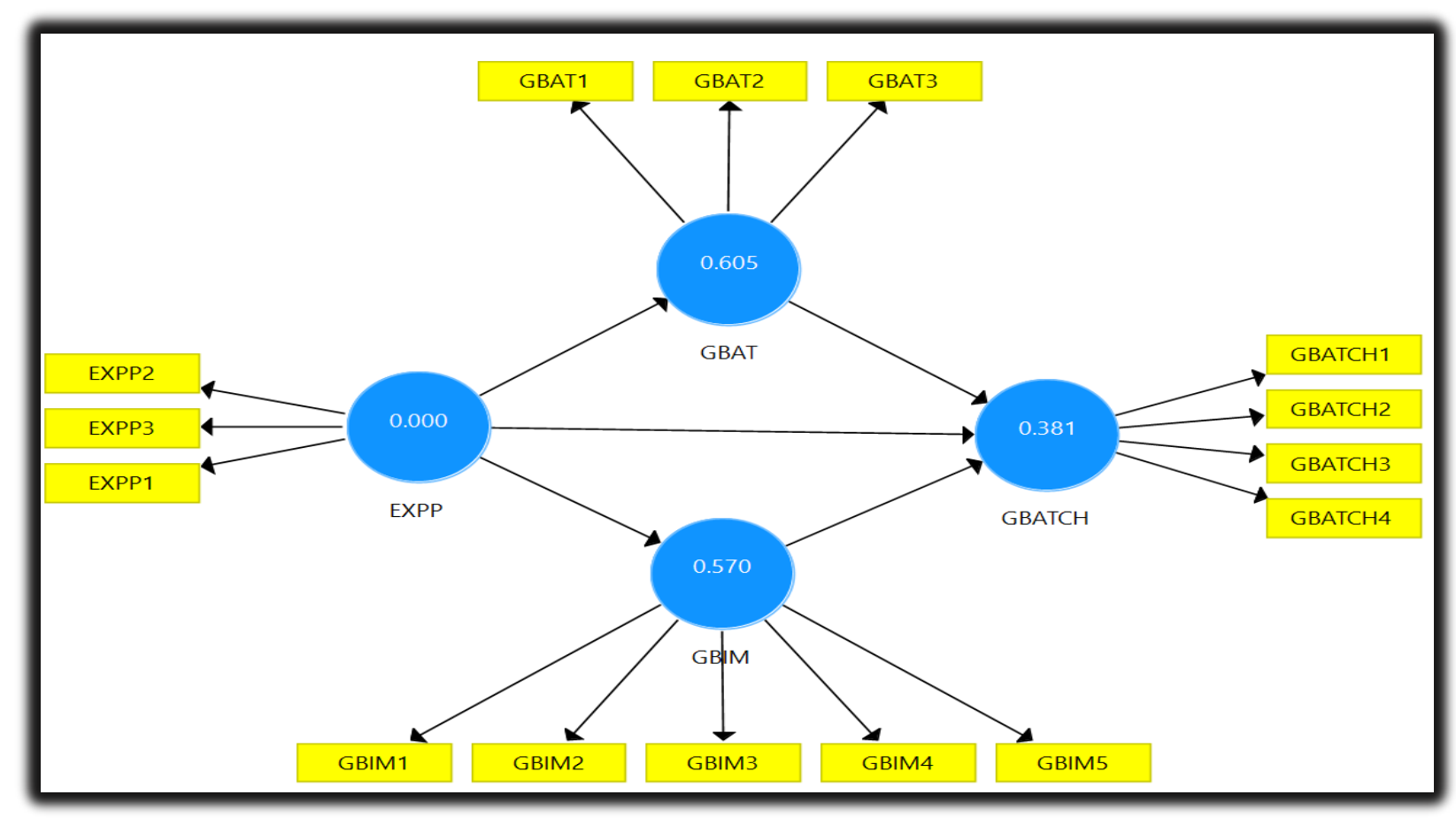

Figure 3. Q-square.

\section{CONCLUSION}

A research framework has been proposed by this study about analysing the influence of excessive packaging of product on the cognition of brand image and attitude of consumer. Therefore, the study addressed the damage, which can be caused to the brand. It has been revealed through results that there is negative relation of excessive packaging of product with the GBAT of consumer and GRIM awareness. The GBATCH is influenced positively by the GRIM and GBAT. The GBATCH of consumer is influenced by the GRIM and GBAT through excessive packaging of product. This causes brand avoidance and results in damages to the brand (Korpela, 2016; Sasmita \& Mohd Suki, 2015). It has been hypothesized that strong obligation and beliefs for reduction in waste are resulted from the increased awareness about the ecology. Green products are purchased by consumers because of their functioning and prevention behaviours. Therefore, the GBAT of consumer is negatively influenced by the excessive packaging of product. The brand and product have an important element, which is Packaging. The packaging part of a product reveals its characteristics, attributes, and shapes the image of the brand. For the marketing of brand, the packaging of product acts as a double edge sword. A vivid and positive image of the brand can be created, which results in negative image of brand for the litter it produces (Suomi et al., 2018). Therefore, the cognition of consumer for the image of green brand can be damaged by excessive packaging of green product. It has been found by study that there is no significant association between GBATCH and excessive packaging of product. The proposed hypothesis is not supported by the results of the study, which stated that the product packaging has the symbolic meaning. Further, it was proposed that the brand attachment would be enhanced by the fear of increasing the environmental issues. The study signifies that GRIM and GBAT play a crucial role in the relation of consumer and brand (Doszhanov \& Ahmad, 2015). It is suggested that the GBATCH experience indirect damaged to the relation of brand and consumer affective. Moreover, the previous literature studies have discussed the problem of excessive packaging from a broader perspective. However, it has not been incorporated as a main variable. This is because of the value of product overridden by the other concerns previously. This has 
result in several studies on the design of packaging to fulfil the preference of consumer and preserve the value of culture. The packaging of product is crucial for the product and brand. The study makes four contributions to the existing literature theoretically. Initially, the concepts of environmental protection and green marketing are combined by this study in the development of research framework to establish attachment of green brand from the aspect of excessive packaging of product, GRIM, and GBAT. The second contribution of the study is the analysis of relation of green band attachment and EXPP, which was not explored previously. The GBATCH cannot be influenced directly by the excessive packaging of product (Doszhanov \& Ahmad, 2015). It creates indirect negative influence on the GBATCH through GRIM and GBAT (Sasmita \& Mohd Suki, 2015). In this way, the identified research gap has been filled. The third contribution of the study is through identifying the relation between GBATCH and EXPP. This relation is mediated by the GRIM and GBAT. The fourth contribution is through exploring that the GBAT and brand image is increased through reduction in the excessive packaging of product. This can create a positive influence on the attachment of green brand. The research on sustainable development and green marketing has been extended by this research. Three practical contributions have been made by this study. The first practical contribution is the verification that the GRIM and GBAT increase with the decrease in excessive packaging of product. When companies aim at increasing the attachment to green brand for their product selection, the products with excessive packaging should be avoided. The second contribution is the context of sophistically marketing. It is important to give awareness to the retailers, which are the source of communication between the producers and consumers to reduce the excessive packaging of product to improve the attachment to green brand. There is need for the companies to improve the GRIM and GBAT. In this research, the GRIM and GBAT act as mediators (Papista \& Dimitriadis, 2019). The study reveals that GRIM and GBAT can result in improved attachment to green brand. The results of the study found that it can be understood by the companies that eco-friendly packaging of product van reduce the issues of environment along with other potential benefits. Eco-friendly packaging results in low cost for warehousing and transportation. It fulfils the requirements of consumers about use of green materials. Moreover, green consumers are attracted through eco-friendly packaging. The brand is evaluated positively when the consumers possess positive emotions and vice versa. The brands should not be linked with any negative experiences or content including excessive packaging (Knittel et al, 2016). The value promotion of environmental problem solving, or green branding can be contributed by the green packaging. The companies should not overdo it. The psychological reactance theory suggests that when the social pressure to avoid excessive packaging is increasing, the opposite behaviour will be exhibited. For both enterprises and consumers, it is true. The concerns of consumers increase for the green brands and green products. For enhancing the benefits of green products in terms of functions, the companies should value the brand and give importance to the damages besides the green packaging of product. Most of the enterprises are experiences issues in creating a balance between the issues of environmental protection and financial profitability. It becomes important to resolve the issue of ecofriendly packaging of product and product promotion. It has been suggested by this study that there is need for companies to focus on the positioning of brand and consumer attraction through beautiful product packaging. The products, which are green, are positioned as those protecting the environment. In this way, natural products are providing that yield the same functional benefits as compared with the normal products. However, the green products address the issues of environment. Therefore, the marketing of green brand should focus on the basic value of brand for the green consumers. The target respondents in this study comprised on young generation. In this way, the study cannot reflect the situation for all the consumers. Moreover, the definition of excessive packaging of product differs with the type of products. Therefore, it is not recommended for the future studies to work on analysing the packaging issue for different type of product. Further, it is suggested that experimental design methodology can be adopted by future studies to test the related topics regarding the excessive packaging of product. 


\section{REFERENCES}

Ahn, J., \& Back, K.-J. (2018). Influence of brand relationship on customer attitude toward integrated resort brands: a cognitive, affective, and conative perspective. Journal of Travel \& Tourism Marketing, 35(4), 449-460. https://doi.org/10.1080/10548408.2017.1358239

Ansary, A., \& Hashim, N. M. H. N. (2018). Brand image and equity: The mediating role of brand equity drivers and moderating effects of product type and word of mouth. Review of Managerial Science, 12(4), 969-1002. https://doi.org/10.1007/s11846-017-0235-2

Banerjee, S. B. (2017). Corporate environmentalism and the greening of strategic marketing: Implications for marketing theory and practice Greener Marketing (pp. 16-40): Routledge. https://doi.org/10.4324/9781351283083-1

Carrión, G. C., Henseler, J., \& Roldán, J. L. (2016). Prediction-oriented modeling in business research by means of PLS path modeling: Introduction to a JBR special section. Journal of Business Research, 69(10), 4545-4551. https://doi.org/10.1016/i.jbusres.2016.03.048

Challcharoenwattana, A., \& Pharino, C. (2016). Wishing to finance a recycling program? Willingness-topay study for enhancing municipal solid waste recycling in urban settlements in Thailand. Habitat International, 51, 23-30. https://doi.org/10.1016/..habitatint.2015.10.008

Charlton, A. B., \& Cornwell, T. B. (2019). Authenticity in horizontal marketing partnerships: A better measure of brand compatibility. Journal of Business Research, 100, 279-298. https://doi.org/10.1016/i.jbusres.2019.03.054

Chen, Y.-S., Hung, S.-T., Wang, Ting-Yu, , \& Huang, A.-F., Liao, Yen-Wen. (2017). The influence of excessive product packaging on green brand attachment: The mediation roles of green brand attitude and green brand image. Sustainability, 9(4), 654. https://doi.org/10.3390/su9040654

Choubak, M., Pereira, R., \& Sawatzky, A. (2019). Indicators of Ecological Behaviour Change.

Dangelico, R. M., \& Vocalelli, D. (2017). "Green Marketing": an analysis of definitions, strategy steps, and tools through a systematic review of the literature. Journal of Cleaner Production, 165, 12631279. https://doi.org/10.1016/j.jclepro.2017.07.184

Dechprom, S. \& Jermsittiparsert, K. (2018). Impact of Green Supply Chain Practices on the Environmental Performance: Does Institutional Pressure Matters?. International Journal of Management and Business Research, 8(4), 50-62.

Doran, R., \& Larsen, S. (2016). The relative importance of social and personal norms in explaining intentions to choose eco-friendly travel options. International Journal of Tourism Research, 18(2), 159-166. https://doi.org/10.1002/itr.2042

Doszhanov, A., \& Ahmad, Z. A. (2015). Customers' intention to use green products: The impact of green brand dimensions and green perceived value. Paper presented at the SHS Web of Conferences. https://doi.org/10.1051/shsconf/20151801008

Hair, Hult, G. T. M., Ringle, C., \& Sarstedt, M. (2016). A primer on partial least squares structural equation modeling (PLS-SEM): Sage publications. https://doi.org/10.3926/oss.37

Hair, Hult, G. T. M., Ringle, C. M., \& Thiele, K. O. (2017). Mirror, mirror on the wall: a comparative evaluation of composite-based structural equation modeling methods. Journal of the Academy of Marketing Science, 45(5), 616-632. https://doi.org/10.1007/s11747-017-0517-x

Hair, Sarstedt, M., \& Hopkins, L., Kuppelwieser, Volker. (2014). Partial least squares structural equation modeling (PLS-SEM) An emerging tool in business research. European Business Review, 26(2), 106-121. https://doi.org/10.1108/ebr-10-2013-0128

Henseler, J., Ringle, C. M., \& Sarstedt, M. (2015). A new criterion for assessing discriminant validity in variance-based structural equation modeling. Journal of the Academy of Marketing Science, 43(1), 115-135. https://doi.org/10.1007/s11747-014-0403-8 
Huang, R., \& Sarigöllü, E. (2014). How brand awareness relates to market outcome, brand equity, and the marketing mix Fashion Branding and Consumer Behaviors (pp. 113-132): Springer. https://doi.org/10.1007/978-1-4939-0277-4_8

Hwang, E., Baloglu, S., \& Tanford, S. (2019). Building loyalty through reward programs: The influence of perceptions of fairness and brand attachment. International Journal of Hospitality Management, 76, 19-28. https://doi.org/10.1016/j.ijhm.2018.03.009

Janadari, M., Sri Ramalu, S., \& Wei, C. (2016). Evaluation of measurment and structural model of the reflective model constructs in PLS-SEM.

Jayaram, J., \& Avittathur, B. (2015). Green supply chains: A perspective from an emerging economy. International Journal of Production Economics, 164, 234-244. https://doi.org/10.1016/j.ijpe.2014.12.003

Jermsittiparsert, K., Namdej, P., \& Somjai, S. (2019). Green Supply Chain Practices and Sustainable Performance: Moderating Role of Total Quality Management Practices in Electronic Industry of Thailand. International Journal of Supply Chain Management, 8(3), 33-46. https://doi.org/10.1115/1.860281_ch4

Keller, K. L. (2016). Reflections on customer-based brand equity: perspectives, progress, and priorities. AMS review, 6(1-2), 1-16. https://doi.org/10.1007/s13162-016-0078-z

Knittel, Z., Beurer, K., \& Berndt, A. (2016). Brand avoidance among Generation Y consumers. Qualitative Market Research: An International Journal, 19(1), 27-43. https://doi.org/10.1108/qmr-03-2015-0019

Korpela, K. (2016). Consumer evaluations of green brand extensions: The role of parent brand quality and perceived fit.

Kushwaha, G. S., \& Sharma, N. K. (2016). Green initiatives: a step towards sustainable development and firm's performance in the automobile industry. Journal of Cleaner Production, 121, 116-129. https://doi.org/10.1016/j.jclepro.2015.07.072

Leonidou, L. C., Christodoulides, P., \& Thwaites, D. (2016). External determinants and financial outcomes of an eco-friendly orientation in smaller manufacturing firms. Journal of Small Business Management, 54(1), 5-25. https://doi.org/10.1111/jsbm.12121

Loureiro, S. M. C., Sarmento, E. M., \& Le Bellego, G. (2017). The effect of corporate brand reputation on brand attachment and brand loyalty: Automobile sector. Cogent Business \& Management, 4(1), 1360031. https://doi.org/10.1080/23311975.2017.1360031

Love, E., Staton, M., \& Rotman, J. D. (2016). Loyalty as a matter of principle: the influence of standards of judgment on customer loyalty. Marketing Letters, 27(4), 661-674. https://doi.org/10.1007/s11002015-9371-0

Magnier, L., \& Crié, D. (2015). Communicating packaging eco-friendliness: An exploration of consumers' perceptions of eco-designed packaging. International Journal of Retail \& Distribution Management, 43(4/5), 350-366. https://doi.org/10.1108/ijrdm-04-2014-0048

Magnier, L., \& Schoormans, J. (2015). Consumer reactions to sustainable packaging: The interplay of visual appearance, verbal claim and environmental concern. Journal of Environmental Psychology, 44, 53-62. https://doi.org/10.1016/j.jenvp.2015.09.005

Mueller, R. O., \& Hancock, G. R. (2018). Structural equation modeling The reviewer's guide to quantitative methods in the social sciences (pp. 445-456): Routledge. https://doi.org/10.4324/9781315755649-33

Pansari, A., \& Kumar, V. (2017). Customer engagement: the construct, antecedents, and consequences. Journal of the Academy of Marketing Science, 45(3), 294-311. https://doi.org/10.1007/s11747-016$\underline{0485-6}$ 
Papista, E., \& Dimitriadis, S. (2019). Consumer-green brand relationships: revisiting benefits, relationship quality and outcomes. Journal of Product \& Brand Management, 28(2), 166-187. https://doi.org/10.1108/jpbm-09-2016-1316

Ringle, C. M., Sarstedt, M., \& Mitchell, R., Gudergan, Siegfried P. (2018). Partial least squares structural equation modeling in HRM research. The International Journal of Human Resource Management, 127. https://doi.org/10.1080/09585192.2017.1416655

Ryu, K. (2017). Effect of a Brand Story Structure on Perceived Brand Image: The Mediating Role of Immersion in a Brand Story of a Luxury Hotel. Purdue University. https://doi.org/10.1016/j.tourman.2018.10.021

Sarstedt, M., \& Cheah, J.-H. (2019). Partial least squares structural equation modeling using SmartPLS: a software review. Journal of Marketing Analytics, 1-7. https://doi.org/10.1057/s41270-019-00058-3

Sasmita, J., \& Mohd Suki, N. (2015). Young consumers' insights on brand equity: Effects of brand association, brand loyalty, brand awareness, and brand image. International Journal of Retail \& Distribution Management, 43(3), 276-292. https://doi.org/10.1108/ijrdm-02-2014-0024

Simmonds, G., Woods, A. T., \& Spence, C. (2018). 'Show me the goods': Assessing the effectiveness of transparent packaging vs. product imagery on product evaluation. Food quality and preference, 63, 18-27. https://doi.org/10.1016/j.foodqual.2017.07.015

Somjai, S. \& Jermsittiparsert, K. (2019). Role of Pressures and Green Supply Chain Management Practices in Enhancing the Operational Efficiency of Firms: Evidence from Thailand. International Journal of Supply Chain Management, 8(4), 437-445.

Sorunmu, Y. E. (2018). Life Cycle Environmental and Economic Evaluation of Pyrolysis Oil Upgrade Technologies. Drexel University.

Stø, E., \& Strandbakken, P. (2017). Eco-labels and consumers The Future of Eco-labelling (pp. 92-119): Routledge. https://doi.org/10.4324/9781351280808-5

Suomi, K., Luonila, M., \& Tähtinen, J. (2018). Ironic festival brand co-creation. Journal of Business Research. https://doi.org/10.1016/j.jbusres.2018.08.039

Sutduean, J., Joemsittiprasert, W., \& Jermsittiparsert, K. (2019). Supply Chain Management and Organizational Performance: Exploring Green Marketing as Mediator. International Journal of Innovation, Creativity and Change, 5(2), 266-283.

Tzempelikos, N., \& Gounaris, S. (2017). A conceptual and empirical examination of key account management orientation and its implications-the role of trust The Customer is NOT Always Right? Marketing Orientationsin a Dynamic Business World (pp. 673-681): Springer. https://doi.org/10.1007/978-3-319-50008-9_185

\section{@) $\odot \Theta \Theta$}

This work is licensed under a Attribution-NonCommercial-NoDerivatives 4.0 International (CC BY-NC-ND 4.0). 